\title{
САМОИДЕНТИФИКАЦИЯ СУБЪЕКТОВ МАССОВОЙ КУЛЬТУРЫ В УСЛОВИЯХ ОБЩЕСТВЕННЫХ ТРАНСФОРМАЦИЙ
}

\section{SELF-IDENTIFICATION OF MASS CULTURAL SUBJECTS IN THE CONDITIONS OF SOCIAL TRANSFORMATION}

\section{N. Pisarevskaia}

Summary: Interest in the phenomenon of mass culture arose more than a hundred years ago, reflected in many studies in various fields of social and humanitarian knowledge. The main groups acting as subjects of mass culture since the 20th century, in the era of globalization and in many respects the unification of the cultural space, the elite and the masses are considered, since it is they who have a direct impact on the processes taking place in modern society and are active in the field of transformations. Today, comprehension of the ways of self-identification of subjects of mass culture in the context of social transformations, their mutual influence, both at the conscious and unconscious levels, is acquiring special relevance.

Keywords: self-identification, mass culture, subject, mass, elite, transformation.

\author{
Писаревская Наталья Сергеевна \\ К.филол.н., доцент, Московский \\ международный университет \\ n-pisarevsk@mai.ru
}

Аннотация: Интерес к феномену массовой культуры возник более ста лет назад, отразившись во множестве исследований в различных областях социального и гуманитарного знания. Основными группами, выступающими в качестве субъектов массовой культуры, начиная с XX в., в эпоху глобализации и во многом унификации культурного пространства, считают элиту и массу, поскольку именно они имеют непосредственное влияние на процессы, происходящие в современном обществе, и проявляют активность в сфере преобразований. Сегодня особую актуальность приобретает осмысление способов самоидентификации субъектов массовой культуры в условиях общественных трансформаций, их взаимовлияние, как на сознательном, так и на бессознательном уровне.

Ключевые слова: самоидентификация, массовая культура, субъект, масса, элита, трансформации.
Д емократические преобразования индустриальной эпохи обернулись к XX веку формированием «массового общества», которое впоследствии рассматривалось в контексте массового производства, массового потребления, массовой коммуникации и информации и т.д. Особое место в этом ряду заняли исследования массовой культуры и массового искусства с точки зрения их трансформации на протяжении двадцатого столетия.

Противоречивость феномена массовой культуры стала предметом исследования представителей различных областей социально-гуманитарного знания: философии, социологии, искусствоведения и культурологии. Актуальным для XX века стал критический анализ массовой культуры в свете парадигмы экзистенциализма (К. Ясперс, К.Г. Юнг и др.) [17,18], в аспекте тоталитаризма (Х. Ортега-и-Гассет, Г. Маркузе и др.) [12,13], в перспективе перехода к постиндустриальному обществу (А. Тоффлер, Ж. Бодрийяр, Д. Белл и др.) $[3,4,16]$.

В этот же период формируется противоположность классического и неклассического понимания субъекта и субъективности. Классическому пониманию субъекта И. Канта [9], К. Маркса [11] и др. была предложена альтернатива стирания границ между субъектом и объектом в постмодернизме (Ж. Делез, Ф. Гватари и др.) [7]. Свое понимание формирования субъекта в обществе было сформировано в социологии XX века (Э. Дюркгейм и др.) [8]

Методологические основы культурно-исторического понимания личности и ее социализации и самоидентификации были заложены в психологии Л.С. Выготским [6] и получили дальнейшее развитие в трудах психологов и философов. Проблему взаимосвязи индивидуального и коллективного углубленно исследовали отечественные психологи Б.Г. Ананьев, С.Л. Рубинштейн, А.В. Брушлинский и др. $[1,5,15]$

Основными группами, выступающими в качестве субъектов массовой культуры в эпоху глобализации, считают элиту и массу, поскольку именно они имеют непосредственное влияние на все процессы, происходящие в современном обществе, и проявляют активность в сфере социокультурных преобразований. Субъект по определению должен обладать не просто активным, но и творческим началом. В философии, психологии и теории культуры от субъекта неотделимы не только характеристики активности и деятельности, но и творчество как созидание новых форм социального и духовного бытия.

В процессе общественных трансформаций XX-XXI 
вв. складываются противоречивые формы самоидентификации субъектов массовой культуры на уровне массового индивида и элиты. Парадоксальная логика этих трансформаций выразилась в формировании «человека массы» как «псевдоличности». Основанием суррогатных форм его самореализации является произвол, смысл которого не в творческом самосовершенствовании, а в удовлетворении случайной прихоти. При этом случайно-произвольное отклонение в стандартном поведении отличается от творческого преобразования себя и мира.

Самоидентификация формирует и корректирует стиль жизни и поведения, определяет способы общения и культурное пространство, в которые включается индивид. Однако личностная самоидентификация современного человека есть не только соотнесение себя с другим, группой, человечеством, но и осознание своего своеобразия и самотождественности в различных формах - от самопереживания до самосознания и самоанализа.

Самосознание в трактовке классической философии сугубо рационально, самоидентификация в теории культуры и психологии, помимо рационального представления о собственном Я, предполагает иррациональное самоощущение и переживание индивидуального и группового субъекта, вплоть до сознательно-бессознательных реакций индивида и группы, через которые происходит их самоидентификация в массовой культуре. Как пишет Д. Майерс «Мы настолько проникаемся групповым сознанием (отождествляем себя с группой), что не упускаем ни единой возможности думать о себе как о группе и, следовательно, демонстрируем предрасположенность в пользу своей группы» [10, с.358].

Самосознание представителя элиты в качестве творческой индивидуальности является более отрефлексированной рациональной установкой, которая, тем не менее, в сочетании с конформистским приспособлением к потребностям массы, есть превратно-противоречивый способ его деятельной самоидентификации. Тем самым элита выступает как свое иное массы в качестве субъекта массовой культуры. При этом бессознательный выбор в пользу конформизма при условии сознательных отсылок к своей уникальности и оригинальности - характерный признак самоидентификации субъектов массовой культуры, как на уровне массы, так и элиты.

Искажение процессов самоидентификации и самореализации в массовой культуре обусловлено формированием такого способа самоутверждения у стандартизированного «человека массы», при котором за индивидуальную творческую исключительность и духовную составляющую жизни выдается культивирование прихотей на фоне стереотипов потребления, а также транслирование этих стереотипов на все измерения культуры, посредством которых он проявляет свою субъектность.
Если интеллектуальная и, преимущественно, творческая деятельность делает современную элиту антиподом массы, то замена гуманистического служения высоким идеалам материальным благополучием, социальным статусом и удовлетворением амбиций сближает элиту с массой. Эта взаимодетерминация вкусов и ценностных ориентиров массы и элиты - результат трансформации субъекта культуры. Элита «как бы» детерминирует мировосприятие человека массы, но это не воздействие, а взаимодействие между массой и элитой. Массовая культура определяется всесилием «средних» людей, которые способны диктовать условия элите. На сознательном уровне массовый человек мнит себя уникальной личностью, вербально обособляясь от окружающих, но посредством вовлечения в конформистско-стереотипное поведение, он оказывается выразителем групповой идентичности, в чем проявляется противоречивый способ его сознательно-бессознательной самоидентификации.

На почве массового потребления, которое поддерживается массовой культурой, сегодня происходит взаимодействие элиты и массы как субъектов массовой культуры. При этом представители, как массы, так и элиты становятся «винтиком» в системах, где в основу их субъектности закладывается потребительская идеология. Теперь и элита руководствуется массовыми стандартами. Высший слой общества, выделившийся по принципу обогащения, также начинает потреблять то, что ему предлагается, считая, что именно степень приобретения и качество товара и делает ее элитой. Разница заключается в том, что продукты ее потребления значительно дороже и престижнее, чем то, что имеет масса. Так, наиболее обеспеченные представители общества превращаются в «...потребительскую элиту (группу «А»), служащую моделью для большинства, еще не располагающего соответствующим роскошным набором (спортивный автомобиль, стереосистема, вторичная резиденция), без которого нет европейца, достойного этого имени» [4, с. 98]. Таким образом, представители элиты тоже начинают жить по принципам потребления и коллекционирования, при этом претендуя на уникальность за счет обладания.

Парадоксы самоидентификации субъектов современной массовой культуры связаны с характером деятельности, в которой преобладает рутина, а ее односторонним дополнением становится развлечение. Рутинный труд индустриальной и даже постиндустриальной эпохи компенсируется культурой развлечений, которые целенаправленно и профессионально организуются массовой культурой, транслирующей позитивную сторону консьюмеризма, что преобразуется в суррогатность созидательной самореализации субъекта: «Восприятие окружающего мира искажается, приобретая ярко выраженный экономический подтекст. Люди перестают отделять свои индивидуальность и уникаль- 
ность от материального благополучия и как следствие приобретаемых ими товаров. А утрата личностной уникальности в контексте слияния с обществом на основе потребления ведет к тому, что индивиды сливаются в массу» $[14$, с.70].

Таким образом, в результате общественных трансформаций, сегодня в роли субъектов массовой культуры можно рассматривать массу, личность, претендующую на статус уникальной индивидуальности и элиту, дифференцирующуюся по материальному признаку. При этом современная творческая элита, претендуя на исключи- тельность в творческом плане, фабрикует стереотипы массового потребления, поддерживая существование массовой культуры. Как следствие самоидентификация субъекта массовой культуры как творца оказывается мнимой по причине доминирования материальной потребности над стремлением к идеалу. Капризы вкуса человека массы, с одной стороны, и следование им из меркантильных соображений, с другой, - основа превратной субъектности и массы и элиты, где внешнее противостояние скрывает принципиальную их внутреннюю взаимообусловленность, включая способы самоидентификации.

\section{ЛИТЕРАТУРА}

1. Ананьев, Б.Г. 0 проблемах современного человекознания / Б.Г. Ананьев. - 2-е издание. - Санкт-Петербург: Питер, 2001. - 272 с.

2. Арендт, Х. Истоки тоталитаризма / Х. Арендт - Москва., ЦентрКом, 1996. - 672 с.

3. Белл, Д. Грядущее постиндустриальное общество. Опыт социального прогнозирования. / Д. Белл - М., 2004. - 170 с.

4. Бодрийяр, Ж. Общество потребления: его мифы и структуры / Ж. Бодрийяр. - М.: Республика: Культурная революция, 2006. - 269 с.

5. Брушлинский, А.В. Психология субъекта / А.В. Брушлинский. - СПб.: Алетейя, 2003. - 272 с.

6. Выготский, Л.С. Собрание сочинений: В 6 т. / Л.С. Выготский. - М.: Педагогика, 1983. - 3 Т.

7. Делез, Ж., Гватари Ф. Капитализм и шизофрения. Анти-Эдип. / Ж. Делез, Ф. Гватари. - М.: ИНИОН, 1990.-107 с.

8. Дюркгейм, Э. Социология. Ее предмет, метод, предназначение / Пер. с фр., составление, послесловие и примечания А. Б. Гофмана.- М.: Канон, 1995.352 c.

9. Ильенков, Э.В. Что же такое личность? // Психология личности. Тексты / Под ред. Ю.Б. Гиппенрейтер, А.А. Пузырея.- М.: Изд-во Моск. ун-та, 1982. - 288с.

10. Кант, И. Критика чистого разума / пер. с нем. Н. Лосского- М.: Эксмо, 2011.- 736 с.

11. Майерс, Д. Социальная психология / Д. Майерс - СПб.: Питер, 1997. - 688 с.

12. Маркс, К. Сочинения. 2-е изд. / К. Маркс - М.: Издательство политической литературы, 1960. - 23 Т.

13. Маркузе, Г. Одномерный человек: Исследование идеологии развитого индустриального общества / Г. Маркузе; Пер. с англ., послесл., примеч. А.А. Юдина; Сост., предисл. В.Ю. Кузнецова. - М.: 000 «Издательство АСТ», 2002. - 526 с.

14. Ортега-и-Гассет, Х. Восстание масс: [Пер. с исп.] / Хосе Ортега-и-Гассет - М.: АСТ, 2001. - 509 с.

15. Писаревская, Н.С. Потребление как основа мировосприятия массового человека / Международный научно-исследовательский журнал, № 1-4 (32), $2015-$ - $.69-70$

16. Рубинштейн, С.Л. Основы общей психологии / С.Л. Рубинштейн - СПб.: Питер, 2000. - 713 с.

17. Тоффлер, Э. Шок будущего / Э. Тоффлер - М.: АСТ, 2003. - 557 с.

18. Юнг, К.Г. Феномен духа в искусстве и науке. / К.Г. Юнг - М.: «Ренессанс». 1992.- 320 с.

19. Ясперс, К. Смысл и назначение истории / К. Ясперс - М.: Политиздат, 1991. - 527 с.

() Писаревская Наталья Сергеевна (n-pisarevsk@mai.ru). 